\title{
Advanced Pancreatic Adenocarcinoma
}

National Cancer Institute

\section{Source}

National Cancer Institute. Advanced Pancreatic Adenocarcinoma. NCI Thesaurus. Code C162153.

Pancreatic adenocarcinoma that has spread extensively to other anatomic sites or is no longer responding to treatment. 